\title{
Sistem Pendeteksi Pencemar Udara Portabel Menggunakan Sensor MQ-7 dan MQ-135
}

\author{
Arida Amalia Rosa ${ }^{1}$, Bryan Alexis Simon ${ }^{2}$, Kevin Sherdy Lieanto ${ }^{3}$ \\ ${ }^{1,2,3}$ Program Studi Teknik Komputer, Universitas Multimedia Nusantara, Tangerang, Indonesia \\ arida.rosa@student.umn.ac.id \\ bryan.simon@student.umn.ac.id \\ kevin.sherdy@student.umn.ac.id
}

Diterima 15 Mei 2020

Disetujui 16 Juni 2020

\begin{abstract}
Keterbatasan indera penciuman manusia mendeteksi keberadaan gas-gas yang tidak terlihat dapat membahayakan kesehatan. Oleh sebab itu, diperlukan suatu alat pendekteksi dalam pencemaran udara, sehingga menjadi acuan guna untuk mengetahui tingkat pencemaran udara tersebut. Untuk mendeteksi kadar polusi udara menggunakan sensor gas MQ-7 yang peka terhadap gas karbon monoksida, stabil dan berumur panjang, dan sensor gas MQ-135 yang dapat digunakan untuk menentukan kadar konsentrasi gas amonia, bensol, alkohol. Dan untuk tampilan menggunakan LCD yang sebelumnya di proses oleh mikrokontroler Arduino nano.
\end{abstract}

Index Terms-Air Quality, Gas Sensor, Kualitas Udara, Mikrokontroler, MQ-135, MQ-7

\section{PENDAHULUAN}

Seiring dengan meningkatnya isu pencermaran udara, Direktorat Pengendalian Pencermaran Udara (PPU) yang berada di bawah naungan Kementrian Lingkungan Hidup Indonesia membuat program kerja jangka panjang mengembangkan jaringan pemantauan kualitas udara ambien yang terintegrasi dengan menggunakan peralatan pemantauan otomatis yang beroperasi secara kontinyu yang ditujukan untuk mengetahui kualitas udara ambien di suatu daerah/kota pada waktu tertentu dilakukan oleh pemerintah pusat, pemerintah daerah dan pihak swasta serta pemangku kepentingan lainnya.

KLHK sebagai institusi pengelolaan lingkungan hidup telah membangun peralatan AQMS di beberapa kota. Parameter yang dipantau adalah PM10, PM2.5, $\mathrm{SO} 2, \mathrm{NO} 2, \mathrm{O} 3, \mathrm{HC}$, dan CO. Data yang diterima dari stasiun pemantau kualitas udara, diolah menjadi data ISPU di ruang kendali AQMS KLHK (main center), kemudian data konsentrasi dan ISPU tersebut dikirimkan ke display indoor dan outdoor di masingmasing daerah. Data konsentrasi dan ISPU tersebut digunakan sebagai informasi kondisi kualitas udara kepada masyarakat yang dapat dilihat secara langsung melalui papan tayang (public display outdoor) yang terpasang di pinggir jalan raya. Selain itu, data hasil pemantauan terintegrasi yang dikelola dengan baik dapat digunakan sebagai bahan pengembangan kebijakan dalam pelaksanaan pengendalian pencemaran udara di daerah. Namun meskipun demikian, masih minimnya keberadaan AQMS yang hanya tertanam di beberapa titik di daerah tertentu ini juga memicu kurangnya kesadaran masyarakat akan bahaya dari berbagai polusi udara yang ada.

Projek sederhana ini dibuat dengan harapan bisa meningkatkan kesadaran masyarakat perihal kualitas udara yang terdapat disekitar kita ketika sedang berpergian terlebih karena ukurannya yang juga cukup compact untuk dibawa-bawa. Projek ini pun untuk menunjang program Kementrian Lingkungan Hidup tentang meningkatkan kesadaran masyarakat akan pentingnya memperhatikan ISPU (Indeks Standar Pencemaran Udara).

\section{STUDI LITERATUR}

\section{A. State of the Art}

Pada penelitian ini menggunakan state of the art (penelitian sebelumnya) yang berjudul AirSense: A Portable Context-sensing Device for Personal Air Quality Monitoring (2015) oleh Zhuang, Yan \& Lin, Feng \& Yoo, Eun-Hye \& Xu, Wenyao. sebagai referensi untuk penelitian ini. Adapun state of the art yang digunakan berupa paper untuk dijadikan acuan penelitian, yaitu:

Tabel 1. Acuan state of the art penelitian

\begin{tabular}{|l|lr|}
\hline \multicolumn{2}{|c|}{ Perbedaan } & \multicolumn{2}{|c|}{ Hasil } \\
\hline Pada AirSense pembacaan & Pendekatan berbeda kami \\
kualitas udara berdasarkan dari & lakukan yaitu dengan \\
level debu, GPS, temperatur & pembacaan sensor berdasarkan \\
dan kelembaban yang ada di & kandungan gas dan juga kimia \\
sekitar pengguna sehingga & yang beberapa diantaranya tidak \\
pembacaan terbatas pada & dapat terdeteksi karena \\
parameter tersebut. & keterbatasan indra penciuman \\
& manusia. \\
\hline
\end{tabular}

\section{B. Polusi Udara di Indonesia}

Berdasarkan Laporan Air Quality Life Index Maret 2019 diketahui bahwa dalam dua dekade terakhir kadar $\mathrm{PM}_{2.5}$ mengalami peningkatan yang cukup signifikan dari $8 \mu \mathrm{g} / \mathrm{m} 3$ menjadi $22 \mu \mathrm{g} / \mathrm{m} 3$. Standar 
$\mathrm{PM}_{2.5}$ sendiri adalah partikel yang berukuran 2,5 mikron atau bahkan lebih kecil. Partikel ini tak kasat mata dan bisa terhirup dan menumpuk di paru-paru yag bisa menyebabkan kematian dini pada seseorang. Partikel $\mathrm{PM}_{2.5}$ berasal dari polusi berbagai kendaraan bermotor, kebakaran hutan, pembakaran kayu, minyak, batubara, asap pabrik dan lain sebagainya. $\mathrm{PM}_{2.5}$ juga bisa berada di dalam ruangan, hal ini bisa di picu oleh asap rokok, proses pembakaran saat memasak, pembakaran lilin, dan lain sebagainya.

Berdasarkan data US Environtmental Protection Agency berikut adalah standar level $\mathrm{PM}_{2.5}$ :

Tabel 2. Standar level $\mathrm{PM}_{2}$.

\begin{tabular}{|c|c|c|}
\hline $\begin{array}{l}\text { Kadar } \\
\text { PM }_{2.5}\end{array}$ & $\begin{array}{c}\text { Indeks } \\
\text { Kualitas } \\
\text { Udara }\end{array}$ & Efek Kesehatan \\
\hline $0-12$ & Aman & Tidak ada \\
\hline $\begin{array}{l}12,1- \\
35,4\end{array}$ & Sedang & $\begin{array}{l}\text { Individu yang sensitif bisa } \\
\text { mengalami masalah pernapasan }\end{array}$ \\
\hline $\begin{array}{l}35,5- \\
55,4\end{array}$ & $\begin{array}{l}\text { Tak sehat bagi } \\
\text { kelompok yang } \\
\text { sensitif }\end{array}$ & $\begin{array}{l}\text { Meningkatkan gejala pernapasan } \\
\text { penyakit jantung dan paru-paru }\end{array}$ \\
\hline $\begin{array}{l}55,5- \\
150,4\end{array}$ & Tidak sehat & $\begin{array}{l}\text { Meningkatkan resiko penyakit } \\
\text { jantung, kematian dini bagi } \\
\text { penderita kardiopulmoner dan } \\
\text { meningkatkan risiko pernafasan } \\
\text { populasi umum }\end{array}$ \\
\hline $\begin{array}{l}150,5- \\
250,4\end{array}$ & $\begin{array}{l}\text { Sangat tidak } \\
\text { sehat }\end{array}$ & $\begin{array}{l}\text { Peningkatan } \\
\text { memburuknya penyakit jantung, } \\
\text { paru-paru, kematian dini } \\
\text { penderita kardiopulmoner dan } \\
\text { meningkatnya } \\
\text { populasi umum }\end{array}$ \\
\hline $\begin{array}{l}250,5- \\
500,4\end{array}$ & $\begin{array}{l}\text { Sangat } \\
\text { berbahaya }\end{array}$ & $\begin{array}{l}\text { Risiko kematian diri, penyakit } \\
\text { jantug dan paru-paru }\end{array}$ \\
\hline
\end{tabular}

Dengan Indonesia yang berada pada level sedang saat ini, polusi udara sudah menjadi hal yang perlu dipertimbangkan karna ada kecenderungan peningkatan yang terjadi terus-menerus seiring waktu.

\section{Arduino Nano}

Arduino merupakan sebuah platform dari physical computing yang bersifat open source. Arduino tidak hanya sekedar sebuah alat pengembang, tetapi merupakan kombinasi dari hardware, bahasa pemrogaman dan Integrated Development Environment (IDE) yang canggih. IDE adalah sebuah software yang berperan untuk menulis program, melakukan compiling menjadi kode biner dan mengunggah ke dalam memori mikrokontroler. Salah satu pertimbangan menggunakan Arduino Nano adalah merupakan board mikrokontroler yang berukuran kecil, lengkap dan mendukung penggunaan breadboard yang memudahkan dalam testing dan debugging.

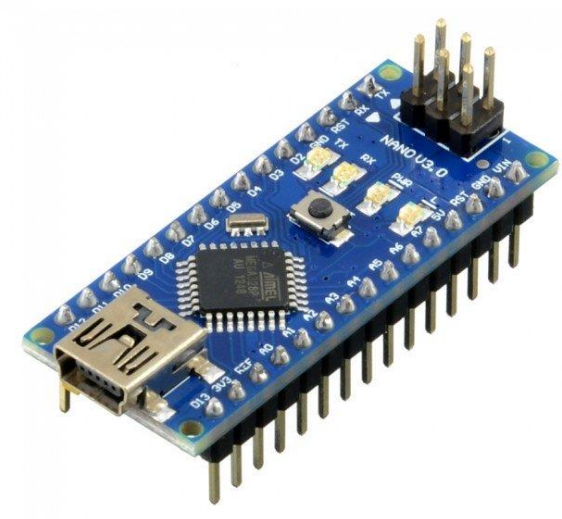

Gambar 1. Arduino Nano

\section{Sensor MQ-135}

Sensor MQ-135 adalah jenis sensor kimia yang sensitif terhadap senyawa NH3, NOx, alkohol, benzol, asap (CO), CO2, dan lain-lain. Sensor ini bekerja dengan cara menerima perubahan nilai resistansi (analog) bila terkena gas. Sensor ini memiliki daya tahan yang baik untuk penggunaan penanda bahaya polusi karena praktis dan tidak memakan daya yang besar. Penyesuaian sensitifitas sensor ditentukan oleh nilai resistansi dari MQ-135 yang berbeda-beda untuk berbagai konsentrasi gasgas. Jadi, Ketika menggunakan komponen ini, penyesuaian sensitifitas sangat diperlukan. Selain itu, kalibrasi pendeteksian konsentrasi NH3 sebesar 100 ppm atau alkohol sebesar $50 \mathrm{ppm}$ di udara.

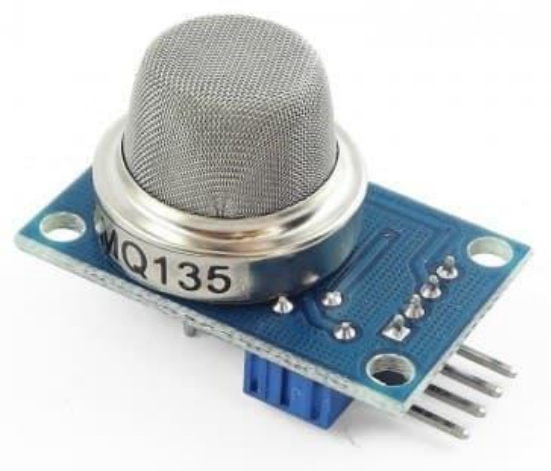

Gambar 2. Sensor MQ-135

Tabel 3. Spesifikasi standar kerja Sensor MQ-135

\begin{tabular}{|c|c|c|}
\hline Parameter & Kondisi Teknis & Keterangan \\
\hline Circuit Voltage & $5 \mathrm{~V} \pm 0,1$ & AC atau DC \\
\hline Heating Voltage & $5 \mathrm{~V} \pm 0,1$ & AC atau DC \\
\hline Load Resistance & Bisa menyesuaikan & \\
\hline Heater Resistance & $33 \Omega \pm 5 \%$ & Suhu ruangan \\
\hline
\end{tabular}




\begin{tabular}{|c|c|c|}
\hline Heating & $<500 \mathrm{~mW}$ & \\
Consumption & & \\
\hline Jangkauan & $10-300 \mathrm{ppm}$ & \\
Pengukuran & ammonia & \\
& $10-1000 \mathrm{ppm}$ & \\
& benzol & \\
& $10-300 \mathrm{ppm}$ alkohol & \\
\hline
\end{tabular}

\section{E. Sensor $M Q-7$}

Sensor MQ-7 merupakan sensor gas yang digunakan untuk mendeteksi gas karbon monoksida (CO) dalam kehidupan sehari-hari. Sensor gas MQ7 ini mempunyai kelebihan sensitifitas yang tinggi terhadap karbon monoksida (CO), stabil, dan usia pakai yang lama. Penyesuaian sensitivitas sangat diperlukan. Disarankan kalibrasi pendeteksian untuk CO 200ppm di udara.

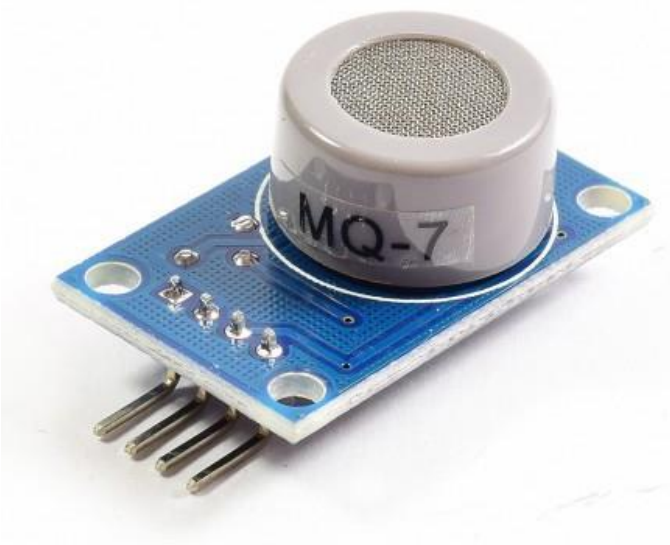

Gambar 3. Sensor MQ-7

Tabel 3. Spesifikasi standar kerja Sensor MQ-7

\begin{tabular}{|c|c|c|}
\hline Parameter & Kondisi Teknis & Keterangan \\
\hline Circuit Voltage & $5 \mathrm{~V} \pm 0,1$ & AC atau DC \\
\hline Heating Voltage & $5 \mathrm{~V} \pm 0,1$ & AC atau DC \\
\hline Load Resistance & Bisa menyesuaikan & \\
\hline Heater Resistance & $33 \Omega \pm 5 \%$ & Suhu ruangan \\
\hline $\begin{array}{c}\text { Heating } \\
\text { Consumption }\end{array}$ & sekitar $350 \mathrm{~mW}$ & \\
\hline $\begin{array}{c}\text { Jangkauan } \\
\text { Pengukuran }\end{array}$ & $\begin{array}{c}20-2000 \text { ppm karbon } \\
\text { monoksida }\end{array}$ \\
\hline
\end{tabular}

\section{F. Polusi Udara}

Pencemaran udara adalah kehadiran satu atau lebih substansi fisik, kimia, atau biologi di atmosfer dalam jumlah yang dapat membahayakan kesehatan manusia, hewan, dan tumbuhan, mengganggu estetika dan kenyamanan, atau merusak properti. Pencemaran udara di dalam ruangan dapat mempengaruhi kesehatan manusia sama buruknya dengan pencemaran udara di ruang terbuka.
Pencemar udara dibedakan menjadi dua yaitu, pencemar primer dan pencemar sekunder. Pencemar primer adalah substansi pencemar yang ditimbulkan langsung dari sumber pencemaran udara. Karbon monoksida adalah sebuah contoh dari pencemar udara primer karena ia merupakan hasil dari pembakaran. Pencemar sekunder adalah substansi pencemar yang terbentuk dari reaksi pencemar-pencemar primer di atmosfer. Pembentukan ozon dalam smog fotokimia adalah sebuah contoh dari pencemaran udara sekunder. Berikut jenis-jenis bahan pencemar udara (polutan): Karbon Monoksida, Nitrogen Oksida, Sulfur Oksida, CFC, Hidrokarbon, Senyawa Organik Volatile, Partikulat, Radikal Bebas.

\section{METODOLOGI DAN IMPLEMENTASI}

\section{A. Komponen yang Digunakan}

- Arduino Nano

Arduino Nano yang berukuran kecil dapat menunjang kebutuhan system yang compact. Arduino Nano juga memiliki Timer Internal sehingga sangat cocok untuk sistem ini.

- $\quad$ Liquid Crystal Display

LCD yang digunakan merupakan Modul LCD 4Pin (Vcc, Gnd, SCA, SCL). LCD akan digunakan untuk menampilkan indikator baterai dan status pembacaan sensor. LCD berkomunikasi dengan Arduino Uno menggunakan protokol I2C.

- $\quad$ Modul MQ-7 Flying Fish

Sensor ini cukup sensitif dengan gas alami, cocok untuk mendeteksi kebocoran gas, mendeteksi karbon monoksida, dan lain sebagainya.

- Modul MQ-135 Flying Fish

Sensor ini mampu mampu mendeteksi NH3, NOx, alkohol, benzena, asap, CO2, dan lain sebagainya.

- $\quad$ LED, Resistor, dan Push Switch Button

LED digunakan sebagai indikator bahwa Arduino Nano berhasil menyala, sedangkan resistor digunakan untuk pull up pada switch. Switch digunakan untuk mengaktifkan mode mute hingga durasi tertentu.

- Modul Step Up

Step Up diperlukan karna baterai yang digunakan hanya menghasilkan tegangan 3,7 Volt sedangkan modul charger yang digunakan memiliki batas maksimal tegangan $5 \mathrm{~V}$ sehingga tidak memungkinkan untuk menggunakan dua baterai, untuk mengatasi hal ini step up digunakan agar tegangan bisa menjadi 5 Volt.

- Module Micro USB Chager

Agar komponen menjadi rechargeable maka diperlukan adanya Modul USB Charger.

- $\quad$ Baterai 2500 Mah 3.7 Volt 
Sebagai sumber daya utama seluruh komponen dari sistem pendeteksi pencemar udara portable.

\section{B. Rancangan Sistem}

B.1 Skematik Hardware

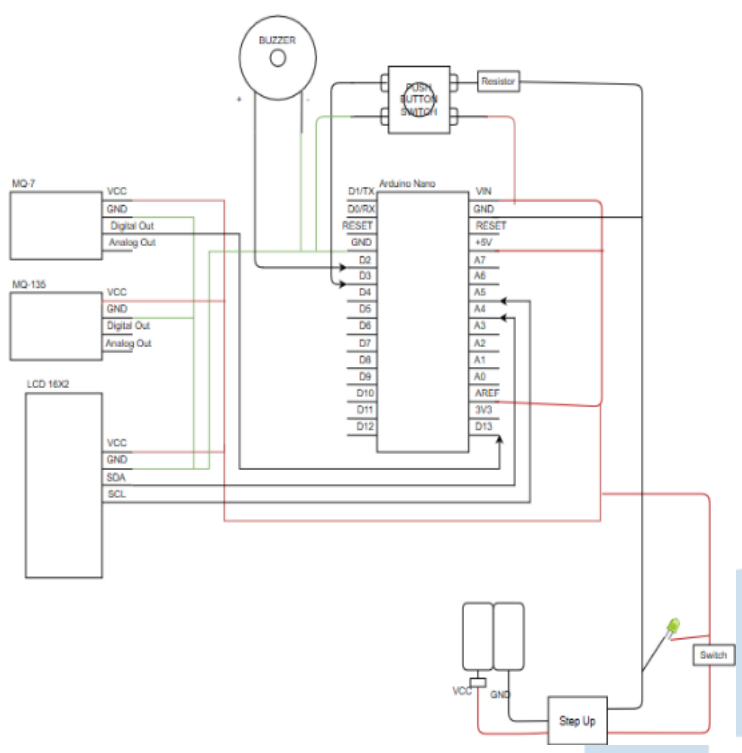

Gambar 4. Skematik perangkat

Gambar 4 menjelaskan skematik rangkaian yang menggambarkan hardware di dalam casing komponen yang kami gunakan.

\section{B.2 Tampilan Perangkat}

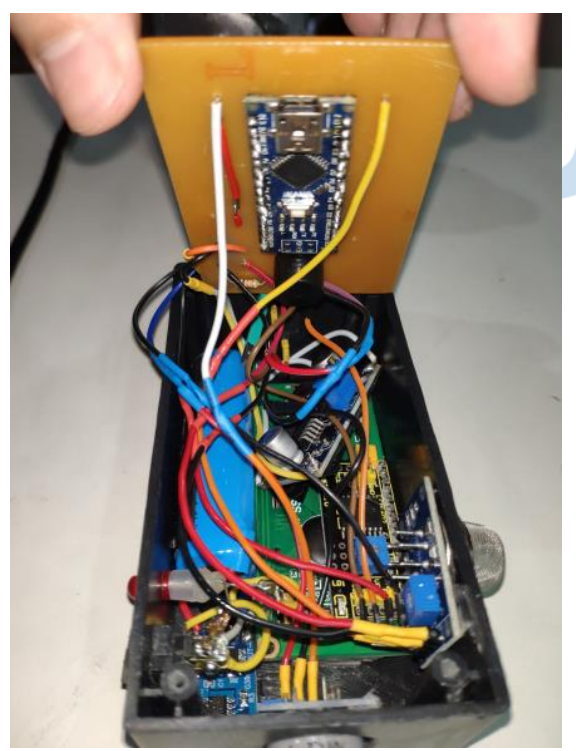

Gambar 5. Tampilan dalam perangkat

Gambar 5 menperlihatkan susunan komponen yang terdapat di dalam casing bedasarkan skematik.

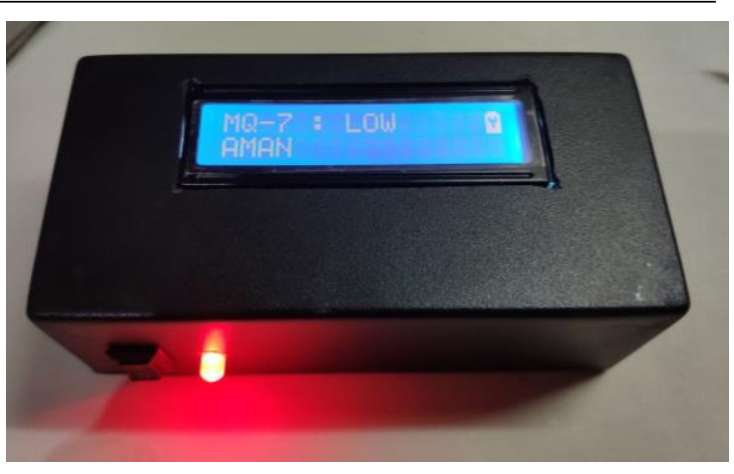

Gambar 6. Tampilan luar perangkat

Gambar 6 memperlihatkan tampilan depan perangkat. Dimana terdapat LCD display yang terdapat bacaan sensor HI/Low, kondisi aman/bahaya, dan daya baterai. Untuk bagian bawah tedapat tombol power, dan led indikator power.

\section{Flowchart Sistem}

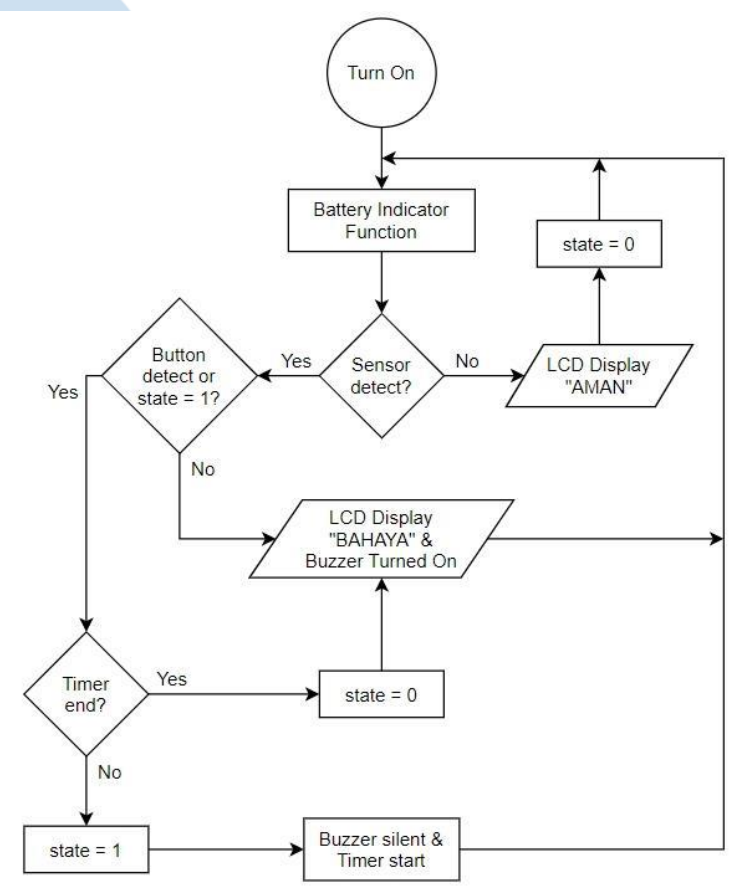

Gambar 7. Flowchart Sistem

Sistem akan melakukan pembacaan terus-menerus. Jika sistem mendeteksi gas melebihi batas yang sudah ditentukan maka akan menghasilkan output untuk memberi informasi kepada pengguna. Pada sistem ini pengguna juga bisa memberikan inputan melalui switch untuk fitur seperti mode senyap.

\section{Implementasi}

Pada saat sistem dinyalakan, sensor akan melakukan pembacaan secara terus menurus. Jika 
sensor mendeteksi adanya gas pada batas tertentu yang sudah diatur, maka sistem akan mengeluarkan output berupa bunyi Buzzer dan tampilan tulisan pada LCD. LCD juga akan menampilkan tingkatan daya dari baterai. Pengguna juga bisa melakukan input untuk mengaktifkan fitur mode senyap dengna menekan tombol saat buzzer berbunyi. Ketika sensor medeteksi adanya gas berbahaya yang sudah melewati ambang dan pengguna menekan tombol, maka sistem akan mengaktifkan mode interrupt sehinga timer akan menghitung mundur selama waktu yang sudah diatur. Namun, jika ditengah perhitungan status sistem kembali ke kondisi "aman" atau mode senyap sudah aktif selama waktu yang sudah ditentukan maka jika kondisi sedang "bahaya" buzzer akan bisa kembali berbunyi. Pengguna juga bisa melakukan isi ulang baterai perangkat menggunakan chager micro USB dengan arus 1 Ampere dan Tegangan 5 Volt.

\section{HASIL DAN ANALISIS}

Berdasarkan peraturan Menteri Perhubungan Nomor 7 tahun 1964 tentang syarat kesehatan, kebersihan serta penerangan dalam tempat kerja dan Peraturan Mentri Tenaga Kerja dan Transmigrasi Nomor PER.13/MEN/X/2011 tentang Nilai Ambang Batas Faktor Fisika dan Faktor Kimia di tempat kerja. Batas kadar monoksida yang dihirup adalah 25ppm, jika melebihi dari itu akan bisa membahayakan manusia.

Untuk standar batas ama alkohol yang terhirup berdasarkan "permissible exposure limits for chemical contaminants" adalah 200ppm.

Pada projek ini simulasi dilakukan dengan menggunakan alkohol. Kami menggunakan alat pengukur polusi udara sebagai pembanding. Dari beberapa percobaan yang kami lakukan didapatkan hasil sebagai berikut.

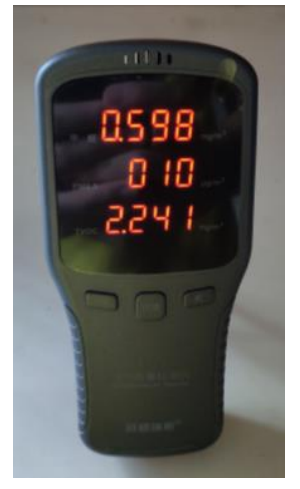

Gambar 8. Pengukuran VOC alkohol jarak 10cm

Gambar 8 menunjukan alat deteksi konsentrasi partikel yang digunakan sebagai pembanding dengan alat yang kami gunakan. Alat ini sekarang sedang menunjukan hasil pengukuran konsentrasi alkohol yang di semprotkan dengan jarak $10 \mathrm{~cm}$.

Berdasarkan artikel Center for Hazardous Substance Research di Kansas State University yang berjudul "Understanding Units of Measurement" dijelaskan bahwa:

Konsentrasi di Udara (ppm) $=24.45 \mathrm{x}$ konsentrasi $\left(\mathrm{mg} / \mathrm{m}^{3}\right) \div$ berat molekul

Pada proses pengujian, zat yang digunakan untuk simulasi adalah alkohol. Alkohol dipilih karna mudah untuk diuji dan diketahui pasti nilai berat molekulnya sehingga mempermudah proses perhitungan. Pengujian pada karbon monoksida dan karbondioksida lebih sulit dilakukan karna metode pengumpulan sampelnya yang terbilang cukup sulit untuk mencapai kadar tertentu.

Metode pengujian ini juga dipilih karna keterbatasan waktu selama proses penelitian dan keterbatasan pada rangkaian yang hanya menggunakan sinyal digital. Untuk pengujian yang mendekati nilai sesungguhnya, diperlukan sinyal analog untuk menentukan nilai ppm yang diterima. Sehingga pada metode pengujian ini kami melakukan perbandingan nilai dengan alat ukur lain yang bisa dilihat pada Gambar 8.

Setelah uji coba, nilai volatile organic compounds (VOCs) yang masih memiliki satuan $\mathrm{mg} / \mathrm{m}^{3}$ jika dikonversikan ke ppm didapatkanlah hasil sebagai berikut:

Tabel 4. Hasil konversi VOCs ke PPM

\begin{tabular}{|c|c|c|}
\hline VOC & PPM & Jarak \\
\hline 2,241 & 1,19114 & $10 \mathrm{~cm}$ \\
\hline 1,818 & 0,966307 & $20 \mathrm{~cm}$ \\
\hline 0,828 & 0,4401 & $30 \mathrm{~cm}$ \\
\hline
\end{tabular}

Kami melakukan simulasi pada sistem dengan mengatur potensi pada modul sensor sehingga sensor bisa mendeteksi 1 ppm dari gas yang dapat dideteksi dan didapatkan tampilan sebagai berikut: 


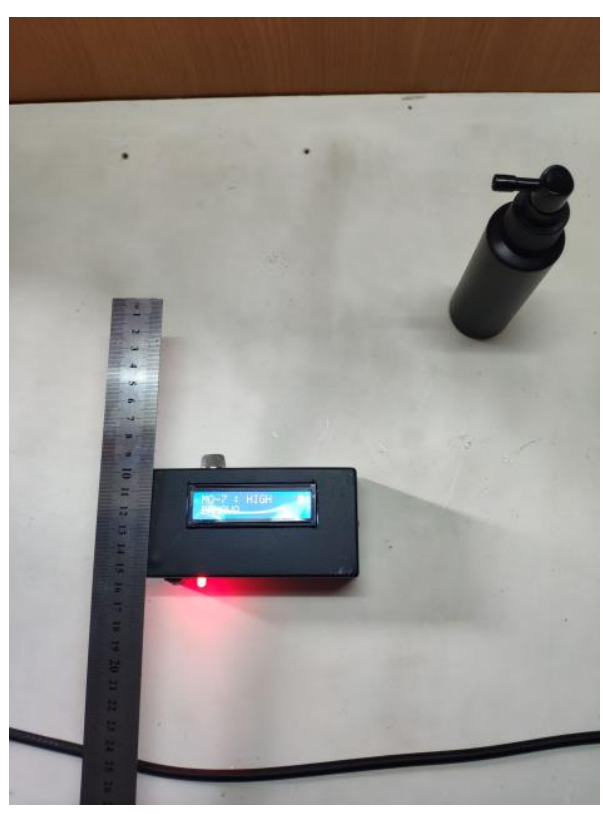

Gambar 9. Percobaan jarak $10 \mathrm{~cm}$

Gambar 11 memperlihatkan proses pengujian alat kami dengan melakukan peyemprotan alkohol dengan jarak $10 \mathrm{~cm}$.

Dari berbagai jarak yang dicoba, didapatkan data sebagai berikut:

Tabel 5. Hasil pengukuran sensor

\begin{tabular}{|c|c|c|}
\hline Jarak Pengujian & Status & Keterangan \\
\hline $10 \mathrm{~cm}$ & Bahaya & - \\
\hline $12 \mathrm{~cm}$ & Bahaya/Aman & Kurang akurat \\
\hline $15 \mathrm{~cm}$ & Aman & - \\
\hline $20 \mathrm{~cm}$ & Aman & - \\
\hline
\end{tabular}

Dari beberapa pengujian dilakukan dapat diketahui bahwa bahwa penggunaan sensor MQ-7 dan MQ-135 sudah cukup ideal untuk melakukan pendeteksian gasgas berbahaya pada batasan tertentu melalui bacaan digital. Namun untuk melakukan pengukuran dengan akurasi tinggi, sensor harus melewati proses heating dan konfigurasi tersendiri melalui pin analog.

Hal ini dikarnakan jika pengukuran RS/R0 dari sensor bisa dihitung maka batasan bisa diatur lebih akurat mengikuti datasheet yang ada. Sedangkan pada percobaan sederhana menggunakan pin digital, pengaturan sensitifitas deteksi sensor dilakukan melalui pengaturan potensio yang hanya bisa diukur tegangannya. Selain itu, bacaan digital yang hanya memberikan 2 jenis output (HIGH dan LOW) dapat memberikan bacaan yang tidak stabil dan berganti terus menerus pada kondisi tertentu, misalnya ketika ukuran ppm dari zat yang terdeteksi memiliki nilai yang berada dekat pada batasan yang diatur pada sensor. Berdasarkan Tabel 4, saat percobaan pada jarak $12 \mathrm{~cm}$ ada kecenderungan pembacaan yang kurang akurat dikarnakan nilai batasan diatur melalui potensio sehingga sulit mengatur nilai akurat dari batas pengujian yaitu $1 \mathrm{ppm}$.

\section{SIMPULAN}

Banyaknya gas berbahaya yang tidak tercium ataupun tidak terlihat membuat rendahnya angka kesadaran masyarakat mengenai bahaya polusi udara. Untuk mengatasi hal ini pemerintah mencanangkan berbagai program yang bisa memperingatkan masyarakat tentang kondisi kualitas udara disekitar mereka. Dengan seiringnya zaman dan tingkat mobilitas masyarakat yang tinggi, dibutuhkan alat pendeteksi kualitas udara yang mudah dibawa kemana-mana.

Sistem Air Quality menggunakan MQ-7 dan MQ135 merupakan salah satu solusi untuk mengatasinya. Sistem ini mampu mendeteksi berbagai gas di udara dan memberikan peringatan untuk masyarakat. Sistem ini cukup untuk mendeteksi gas berbahaya pada kadar yang kita inginkan. Selain mudah dibawa-bawa, perangkat ini juga memiliki fitur lain seperti bisa dilakukan isi ulang daya baterai ataupun mode senyap. Namun untuk perangkat ini tidak dapat melakukan pendeteksian dengan nilai akurasi yang tinggi, hal ini diakibatkan tidak dilakukanya konfigurasi sensor.

\section{DAFTAR PUSTAKA}

[1] OSHA, "Table Ac-1 Permissible Exposure Limits for Chemical Contaminants," Occup. Saf. Heal. Adm., vol. 8, no. d, hal. 1-26, 2019.https://jdih.kemnaker.go.id/data_puu/Permen_5_2018.p df.

[2] D. P. P. dan K. Lingkungan, "Laporan Kinerja Direktorat Pengendalian Pencemaran Udara," 2018.

[3] Permenakertrans, "Peraturan menteri ketenagakerjaan republik indonesia nomor 5 tahun 2018," J. Pendidikan, Teknol. dan Kejuru., vol. 4, no. 2, hal. 200-207, 2018.

[4] https://aqli.epic.uchicago.edu/wpcontent/uploads/2019/03/Indonesia-Report.pdf

[5] Zhuang, Yan \& Lin, Feng \& Yoo, Eun-Hye \& Xu, Wenyao. (2015). AirSense: A Portable Context-sensing Device for Personal Air Quality Monitoring.

[6] https://cfpub.epa.gov/ncer abstracts/index.cfm/fuseaction/dis play.files/fileid/14285

[7] https://www.researchgate.net/publication/329890530_Applica tion of MQ-

138 Semiconductor_Sensor for Breath_Acetone Detection

[8] https://www.epa.gov/pm-pollution/setting-and-reviewingstandards-control-particulate-matter-pm-pollution

[9] https://www.electronicoscaldas.com/datasheet/MQ135 Hanwei.pdf

[10] https://www.sparkfun.com/datasheets/Sensors/Biometric/MQ7.pdf 